\title{
18
}

\section{A systematic approach to the analysis and (re)design of logistic networks}

\section{Telematics support for logistics}

\author{
P.W. van der Veer and R.H.J. Demkes* \\ Telematics Research Centre \\ P.O. Box 589, 7500 AN Enschede, The Netherlands \\ phone: +31534850485, fax: +31534850400 \\ E-mail:veer@trc.nl,demkes@trc.nl
}

\begin{abstract}
This paper describes the approach and first results of current research performed at the Telematics Research Centre (TRC) which focusses on a systematic approach to the analysis and (re)design of logistic networks. In this research, telematics is seen as a supporting technology enabling logistic network improvement.

The first part of the research aims at developing a reference model allowing the investigation of the application of telematics in logistics. This model uses a functional perspective: organisations carry out several functional processes. Insight in these processes and their interactions as well as in the possible telematics services and their interactions is necessary in order to successfully develop telematics applications for logistics.

In the second part, a method is developed for supporting the judgement of the technical, economic, and social aspects of the introduction of telematics, both quantitatively and qualitatively.
\end{abstract}

\section{Keywords}

Feasibility study, logistics, networks, processes, process redesign, quantitative and qualitative factors, reference models, telematics.

\footnotetext{
* The authors would like to thank H. Bakker and P.H.W.M. Oude Luttighuis for reviewing this paper.
} 


\section{INTRODUCTION}

The application of information technology, telecommunications, and telematics in logistics is expanding rapidly. A shift in market power from suppliers to consumers forces these suppliers to provide an increasing variety of products and services. To meet the more demanding needs and wants of customers in an increasing competition, organisations swing back to their core business and cooperate more closely with other organisations. The number of organisations involved in the process of providing customers with products and services, is growing. Not only the products and services themselves, but also the process of realisation is becoming more complex. The focus has shifted from one or several individual organisations towards chains and networks of many cooperating organisations. In these chains and networks, production, transport, and distribution are more and more considered equally important. Of course, improvements in efficiency can be brought about by optimising these processes individually. The real challenge however, is to increase efficiency and effectiveness by improving the functioning of entire chains and networks. Because coordination and therefore information is essential for this improvement, information technology, telecommunications, and telematics can and already do play an important role.

\section{Research structure}

The research consists of two parts. In the first part, described in Sections 2, 3, 4, and 5 , insight is gained into logistic processes and their relations. A focus on processes instead of on organisations is necessary to optimise or (re)design these process structures without being 'blinded' by organisational limitations. Organisations execute and have interests in (parts of) these processes. Therefore we will describe organisations by functional networks, i.e. networks of interacting processes. Whenever we mention logistic networks in this paper, we refer to these functional networks.

Based on insight into logistic process structures, we can determine how a logistic network can be optimised using telematics applications. This insight is gained by developing a reference model. This model describes the generic logistic and telematics process structures and the way they interact. Specific situations can be described by applying these generic structures to specific situations, in other words, by instantiating the model.

Despite the fact that the application of telematics can contribute to the improvement of the related processes, telematics applications are not always successful. Many telematics projects cost more than they have yielded. Therefore, it is vital to have insight into the costs and benefits of telematics applications and the associated changes in the processes involved, from a technical, economic and social perspective.

In the second part of our research, described in Sections 6 and 7, attention is paid to the development of a method to enable organisations to decide whether or not to change their processes by investing in telematics. The method supports judgements of technical, economic, and social aspects, both quantitatively and qualitatively.

In Figure 1, the relation between the reference model and the method is shown. Using the model we can describe an actual situation and a new situation in which 
telematics is used. Based on these descriptions (instances of the model), the method can be used to determine whether a change from the actual to the new situation can be successful.

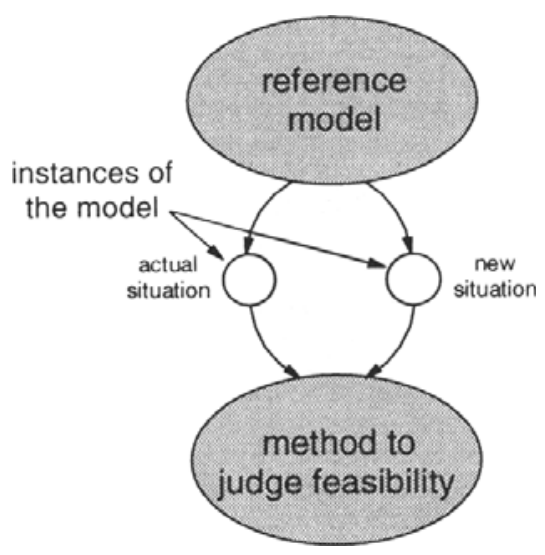

Figure 1 Research structure.

Our approach focusses upon logistic processes, the interactions between those processes, and the feasibility of (re)designing those processes using telematics applications. In other words, our approach focusses on the application domain. Therefore, it can be used in addition to approaches which focus on the (enterprise) design domain, like the Computer Integrated Manufacturing Open System Architecture (CIMOSA), see for example Williams et al. (1994), and Open Distributed Processing (ODP), see Van Sinderen et al. (1995).

\section{Problem area}

Telematics can be defined as the support of the interaction between people and/or processes while bridging distance and/or time, through the integrated application of information and telecommunication technology. Because of its distributed character, logistics is an important application area for telematics. See for example Lewis (1986) and Taylor (1991).

Broadly speaking, logistics in a commercial context comprises all processes aimed at planning, implementing, and controlling the total flow of goods starting at the gaining of raw materials up to the delivery of final products to their end customers. It does not only concern the short-term management of this flow of goods, but also encompasses decision making and management on a more strategic level. Besides the processes directly related to the flow of goods, supporting processes are also taken into account. For a more detailed description of logistics, see for example Bowersox et al. (1986), Van Goor et al. (1993), and Lambert and Stock (1993).

In literature, several logistic subsystems are distinguished, such as supply logistics, production logistics and distribution logistics (Pfohl, 1990). In our research, we do not focus on one or several specific subsystems, but we aim at all processes involved in the physical flow of goods through one or several organisations. This comprises physical, control, and support processes. 


\section{OBJECTIVE AND MOTIVATION FOR A REFERENCE MODEL}

To find out how telematics can be applied for improving logistic networks, it is necessary to have insight into the processes to be supported and their mutual relations. A model can provide this insight. Therefore, in the first part of the research, a reference model is developed, supporting a systematic approach to analyse and (re)design logistic networks and the role of telematics therein. A reference model expresses the general and overall problem domain. Specific situations, like current and future network situations, are obtained by instantiating this model.

\section{Models for telematics and logistics}

Within the field of logistics and telematics, a lot of models with different purposes are available, see e.g. Schuurman (1994). However, most of these models are aimed at specific organisations or specific parts of logistic chains or networks, but not at entire networks. There are for example many mathematical models which calculate specific values given a certain set of input data. Examples are models for determining the optimal location of a distribution centre or the most favourable route for a vehicle. Mathematical models in themselves however, are not sufficient for describing all relevant aspects of logistic processes and their relations. Not only the interdependence of quantitative factors, but also a view on process structures is important. Reference models can make these process structures transparent.

Within our problem domain, different reference models are available. For example, reference models exist for specific subsystems, such as production logistics (Biemans, 1989), or for specific telematics applications in specific logistic subsystems, such as fleet management systems in distribution logistics (Schrijver, 1993). Also, reference models for generally applicable telematics applications are available, such as EDI (Hofman, 1994). Van der Aalst (1992) developed a systematic approach for modelling logistic systems. An integrated, systematic, and scientific approach of telematics applications within logistics however, is lacking at this moment.

\section{A REFERENCE MODEL FOR TELEMATICS AND LOGISTICS}

Our approach is based on the viewpoint that telematics technology is supporting the application domain processes. Therefore, the successful development of telematics applications requires insight into this application domain. Hence, our model consists of two submodels: a logistic and a telematics submodel. In the following, we will introduce the basic concepts, i.e. building blocks, used in both submodels: process, interaction, entity, service, and organisation.

\section{Process}

An important observation is that, both in telematics and in logistics, processes occur which determine the behaviour of telematics and logistic systems. A process can be 
looked upon as a black-box with a particular input and a particular output. The behaviour of a process consists of the interactions with other processes and the timeand-value dependencies between these interactions.

In this paper, we start with a classification of physical processes, i.e. the main processes in logistics. We will refer to them as primary processes. All other processes will be referred to as secondary processes. Note that the terms 'primary' and 'secondary' are not relative to organisations. A secondary process in our perspective can easily be the most important, in other words, the primary process of an organisation.

\section{Interaction}

Two processes are related when they are engaged in interaction. In interactions, entities are exchanged between those processes. Interactions define the relation between two processes, but allow us to abstract from the implementation and the form of exchange. An interaction takes place at an interaction point, which may or may not have a fixed geographical location.

\section{Entity}

An object exchanged in interaction will be referred to as entity. Every process can exchange one or more entities. Entities can be physical objects, like raw materials and products. These objects are part of the flow of goods. However, there are also physical entities which cannot be included in this flow, such as means of production and transport. Therefore, we will refer to the first kind of entities as goods and to the second as resources. Resources are used by processes to perform their operations. Management of these resources is important, because their capacity is often limited.

Besides these physical entities, information can be recognised. Information can be exchanged horizontally, i.e. between information processes, or vertically, i.e. as control information, between control and controlled processes.

\section{Service}

Our classification of primary processes results in a layered structure. Every layer represents a class of processes and offers a service to the layer above. The top layer offers the final service to the end customer. This service concept is also used in the Open Systems Interconnection (OSI) reference model. This model, developed by the International Organisation for Standardisation (ISO), is aimed at structuring open distributed systems, see among others ISO (1984) and Tanenbaum (1981).

The service concept is the strength of the reference model. Layer $\mathrm{N}$ is only concerned with the service provided by layer $\mathrm{N}-1$. How this service is provided by layer $\mathrm{N}-1$, is of no interest to layer $\mathrm{N}$. Irrelevant aspects can therefore be discarded. By using this service perspective, the user is relieved from technical and implementation problems. Also, it is easier to identify services independent of whether or not they are already provided by existing protocols and products. 


\section{Organisation}

In our reference model, another important concept is organisation. An organisation in our model carries out a cluster of processes and can therefore be described in terms of these processes. In the method for the a priori judgement of technical, economic and social aspects of telematics applications in logistics, organisations play a crucial role.

Using these generic concepts, we have developed a first version of a reference model for telematics and logistics. This version has been developed largely as part of the 'Raamwerkstudie Telematica-Infrastructuur Verkeer en Vervoer'. This project, which has been carried out by the Dutch Ministry of Economic Affairs, the Ministry of Transportation, seven consultancy organisations and two research institutes, was aimed at analysing the possibilities of telematics services in traffic and transport and has resulted in strategy and policy recommendations for both government and industry. The model served as a framework used for describing the desired functionalities and services for a telematics infrastructure (Liefting et al., 1994).

\section{THE LOGISTIC SUBMODEL}

Based on the principle of horizontal stratification, we will divide the primary processes in logistics into four layers, see Section 4.1. Because the layered structure is based on a classification of the primary processes, these processes are always bounded to one layer. Although secondary processes can be part of several layers, we will describe them layer by layer in Section 4.2. Section 4.3 shortly describes the role of organisations within these layers and Section 4.4 refers to similar layered logistic structures found in literature.

\subsection{Logistic services}

The world of logistics can be looked upon as a complex system consisting of a large variety of related processes. We used the primary processes to classify these processes into four clusters, each representing one layer in our logistic submodel. We start with distinguishing the USE processes from the logistic service. Then we will decompose this logistic service into COLLECT/SEPARATE processes and a transport service. Finally, this transport service will be decomposed into MOVE processes and a traffic service. Because the traffic service is not part of the world of logistics, we will end our decomposition at this service.

\section{USE processes and the logistic service}

At the highest level, we distinguish the USE processes and the underlying logistic service. The USE processes are all social and economic processes which make use of the movement of persons and goods. These processes, such as production and assembly, change the form of these goods. They require supply of components, transport of final products, and transport of employees. But the same processes might also be observed in health care or in the social sector. These processes have in common that they generate the demand for the movement of goods and persons: they 
send and receive shipments. Therefore the USE processes can be divided into sending and receiving processes. A sending process can send both persons and goods, for example an air traveller with his luggage. In our research, we will only consider production-oriented processes and the movement of goods.

The logistic service provides in the end-to-end transport of shipments. The interaction between the USE processes and the logistic service therefore consists of the exchange of shipments on the interaction points, which have a fixed geographical location. The realisation of the logistic service is not relevant for the USE processes, as long as quality-of-service agreements like delivery time and delivery reliability are met.

The USE processes, the logistic service, and their interaction points are depicted in Figure 2.

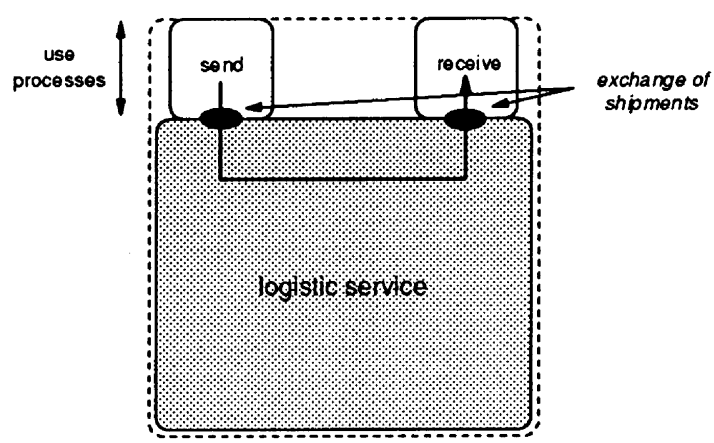

Figure 2 USE processes and the logistic service.

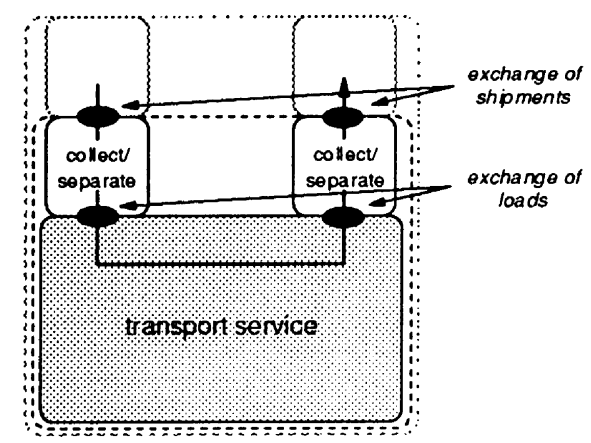

Figure 3 COLLECT/SEPARATE processes and the transport service.

\section{COLLECT/SEPARATE processes and the transport service}

We decompose the logistic service into COLLECT/SEPARATE processes and an underlying transport service. Besides collecting and separating goods, these processes also include packing and unpacking, storing, and transferring goods. They include all processes needed to prepare shipments for transport. The transport service provides in the end-to-end transport of loads. We consider a load as a collected or separated shipment which is offered for transportation to the underlying transport service. So, to use the transport service, exchange of loads at the interaction points is necessary. These interaction points have a fixed geographical location. We can for example think of loading and unloading facilities at distribution centres. The COLLECT/SEPARATE processes, the underlying transport service, and their interaction points are depicted in Figure 3.

In many cases, COLLECT/SEPARATE processes are executed stepwise. Therefore, we can make a further horizontal stratification of this layer into a number of sublayers. See Figure 4. Between those sublayers collection units are exchanged, such as boxes, pallets and containers. A collection unit of the highest level is called a shipment and a collection unit of the lowest level is called a load. Each of the sublayers provides a transport service for collection units of a certain level using the underlying transport service: the transport of collection units of a lower level. A specific sublayer can for 
example provide in the end-to-end transport of pallets by consolidating these pallets into a container and using the underlying end-to-end transport service for containers. In practice the number of sublayers will differ. This number has a minimum of one, but has no maximum.

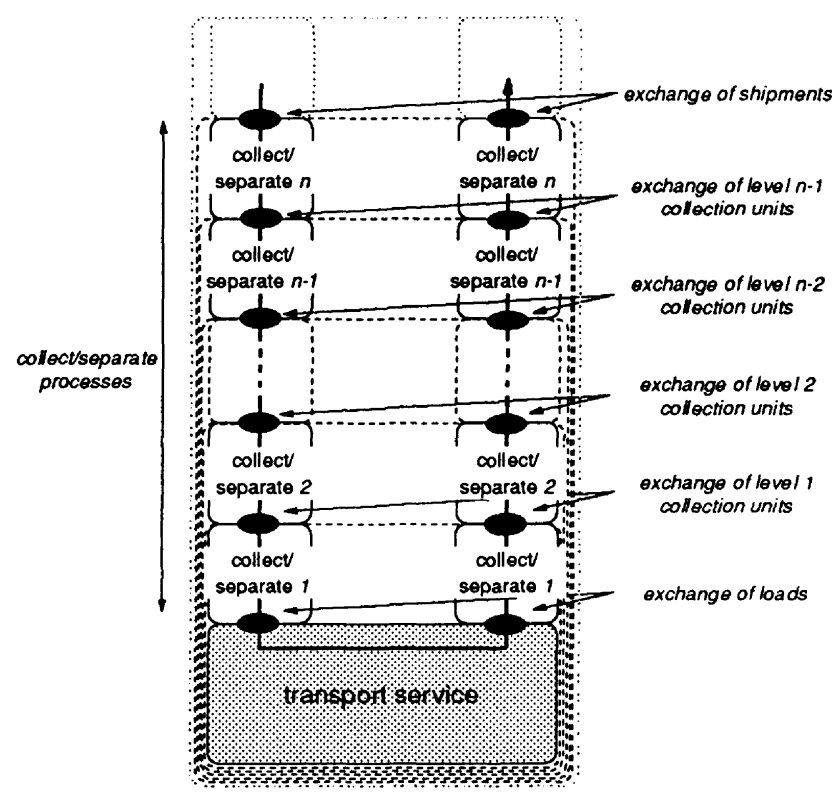

Figure 4 Decomposition of COLLECT/SEPARATE processes into sublayers.

The term COLLECT/SEPARATE processes suggests that collection always takes place at the sending side and separation at the receiving side. However, this is not true. Several types of collection and separation can be distinguished, which can occur in different combinations. Each sublayer can only be related to one type. An example of a specific type of collecting/separating is the separation of an air traveller from his luggage preceding the flight. At the same occasion, this traveller joins other passengers during this flight.

\section{MOVE processes and the traffic service}

The transport service takes care of transport, in other words, the physical movement of offered loads. These processes change the location of goods. For this purpose, different means of transport can be used. We decompose the transport service into MOVE processes and an underlying traffic service. Moving the offered loads using means of transport is only possible by making use of the traffic service, which provides the carrying of means of transport.

The interaction between these MOVE processes and the underlying traffic service is different from the earlier mentioned interactions. In contrast with the exchange of shipments and loads, the movement of means of transport does not take place at one physical location. The geographical location of this interaction point is continuously changing because of the movement of the means of transport. See Figure 5. The MOVE processes are depicted as one block, because there is no functional difference between MOVE processes at the sending side and MOVE processes at the receiving side. 


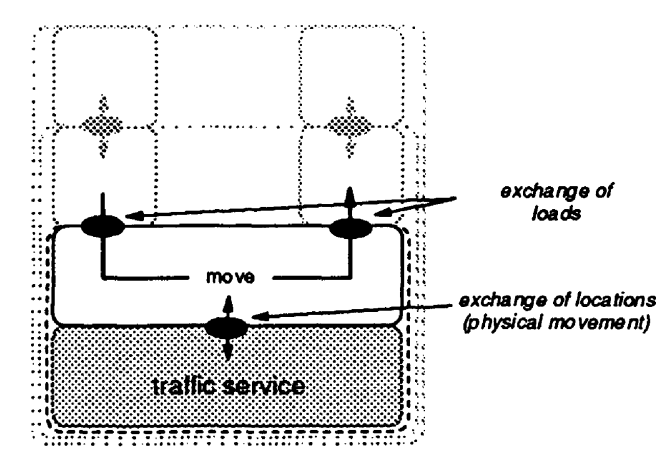

Figure 5 MOVE processes and the traffic service.

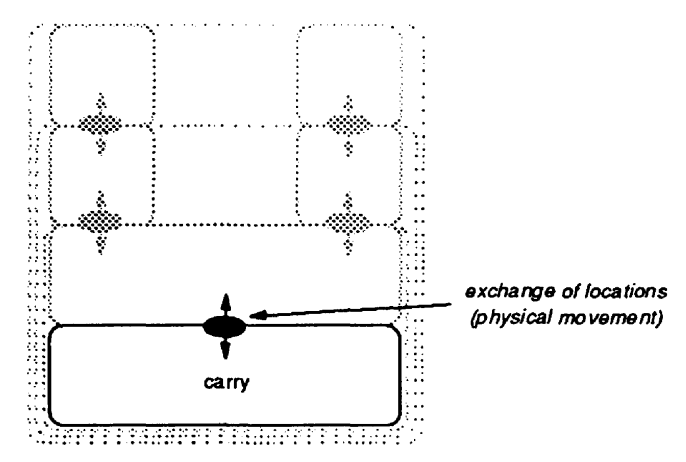

Figure 6 Traffic service.

The MOVE processes require means of transport for operation. Examples of means of transport are trucks, planes, and ships. Besides individual means of transport, also fleets of means of transport can be distinguished. This difference however, does not occur in the primary processes, but in the control, i.e. secondary, processes. In other words, a fleet of means of transport is only a fleet because it is controlled integrally, not because it is one physical object. Secondary processes are described in Section 4.2.

\section{Traffic service}

The traffic service provides a traffic infrastructure which carries the means of transport of the MOVE processes above. In maintaining a high-quality traffic service, traffic control (a secondary process) plays an important role. We will make a further distinction between primary and secondary processes in Section 4.2. Because the traffic service is necessary to perform logistic processes, we added this service to our model. However, because the traffic service is of minor importance to logistic chain and network control, we will not further decompose the primary processes within this service. The traffic service is shown in Figure 6.

The traffic processes provide traffic infrastructures to carry means of transport. Examples of these infrastructures are the air, rail, road, and water infrastructures. We will refer to them as modes of transport.

Modes of transport can only support specific means of transport. However, this is not a one-to-one relation. For example, the road infrastructure can be used by bicycles, cars, trucks, buses, etc. This is an example of a one-to-many relation. Other examples are means of transport which can use several modes of transport, like amphibious vehicles. This is an example of a many-to-one relation.

\section{The four layers}

To refer to (parts of) this described model easily, we distinguish the layers USE, COLLECT/SEPARATE, MOVE and CARRY. The relation between those layers and the described model is shown in Figure 7. In this paper, we will make use of this simplified representation of the reference model. 


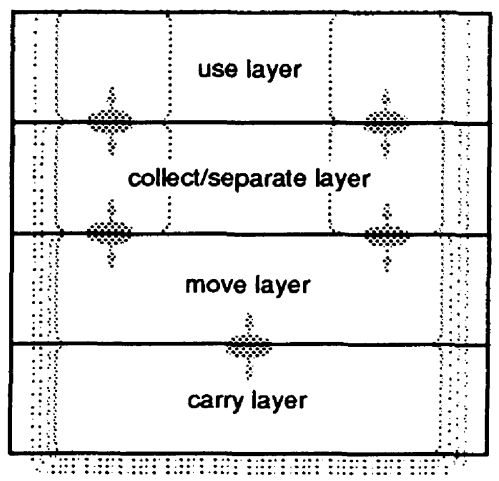

Figure 7 The logistic submodel.

\subsection{Primary and secondary processes}

Primary processes are those processes which are directly involved in changing or moving goods at the different layers. These primary processes are controlled and supported by secondary processes. A secondary process supports and therefore interacts, directly or indirectly, with one or more primary processes.

Secondary processes can be related to primary processes on the sending side, on the receiving side or can be related to distributed primary processes. Secondary processes which are bounded to either the sending or the receiving side, we call local secondary processes. The other processes, which are not bounded to one side, we will refer to as non-local secondary processes.

In this section we will distinguish primary and secondary processes in each layer. Also, a distinction is made between local and non-local secondary processes. In the figures in this section, ' $\mathrm{P}$ ' indicates a primary process, ' $\mathrm{s}$ ' indicates a local secondary process and ' $S$ ' indicates a non-local secondary process.

\section{USE layer}

We can divide this layer into primary processes, local and non-local secondary processes. The primary processes are concerned with changing the form of goods. They all have in common that movement of these goods is necessary in order to provide end users with the desired products. Figure 8 shows the different types of processes which can be recognised in this layer.

An example of a local secondary process is the operational control of a primary process like production or assembly. Examples of non-local secondary processes are production planning, process information exchange and order processing.

\section{COLLECT/SEPARATE layer}

The processes in this layer can be divided into a number of sublayers. In every sublayer, COLLECT/SEPARATE processes take place. On the interaction points between these sublayers, shipments packed in collection units are exchanged. Figure 9 shows the different types of processes which can be recognised in these layers. 


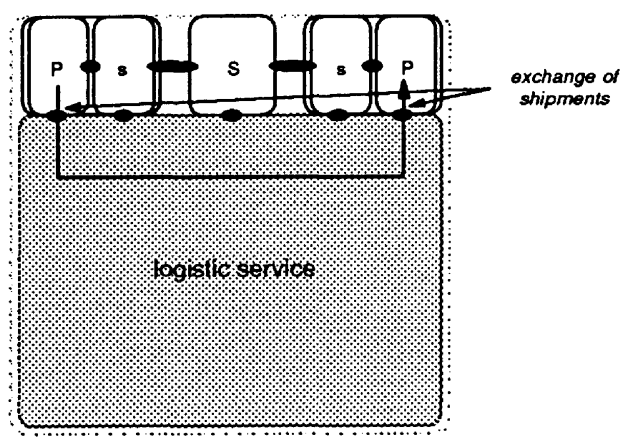

Figure 8 Primary and secondary processes in the USE layer.

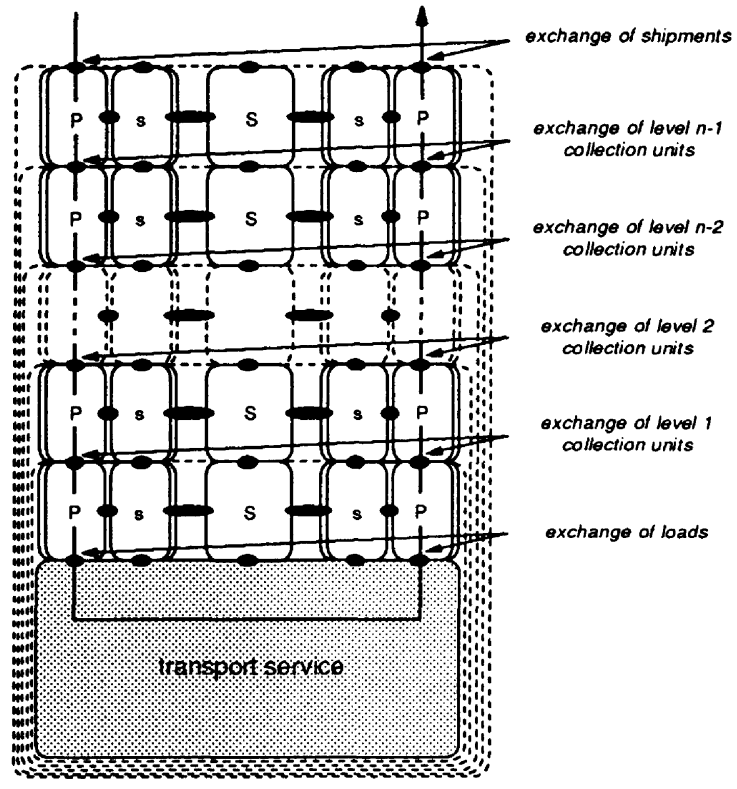

Figure 9 Primary and secondary processes in the COLLECT/SEPARATE layer.

An example of a local secondary process is the operational control of primary processes like packing/unpacking and sorting goods. Examples of non-local secondary processes are collection and separation control, tracking and tracing goods and invoicing.

The information exchange concerning shipments between sublayers takes place in terms of the exchanged collection units. A logistic service provider communicates with the shipper in terms of shipments (articles, boxes, etc.), but the transport service provider in terms of loads (containers, trailers, etc.).

\section{MOVE layer}

The primary processes in the MOVE layer concern the physical movement of means of transport on the traffic infrastructure. In contrast with the USE and COLLECT/SEPARATE layer, we cannot distinguish a sending and a receiving side in this layer. This means that no non-local secondary processes can be identified. However, we can identify local secondary processes, depicted in Figure 10.

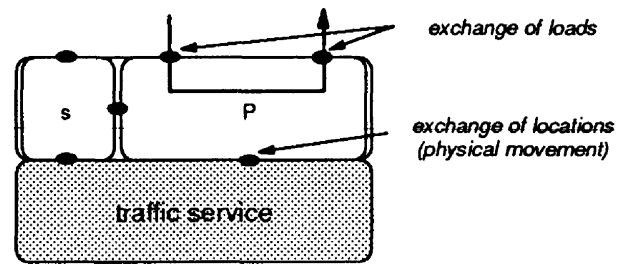

Figure 10 Primary and secondary processes in the MOVE layer.

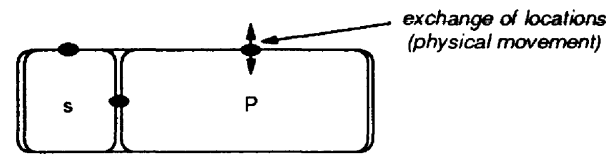

Figure 11 Primary and secondary processes in the CARRY layer. 
For individual means of transport we can for example distinguish the following local secondary processes: operational control of a single means of transport and route planning. An example of a local secondary process for fleets is fleet management.

\section{CARRY layer}

Also in the CARRY layer, only a distinction between primary processes and local secondary processes can be made, see Figure 11 . The primary process of this layer is carrying means of transport. Local secondary processes are for example traffic control, road pricing and incident management.

\subsection{Processes and organisations}

Our layered submodel provides a functional view on logistics. It tells us what happens in terms of 'behaviour'. In our submodel these terms are USE, COLLECT/SEPARATE, MOVE and CARRY. The model so far does not tell us who carries out these processes.

An organisation in our model carries out a cluster of processes in a logistic chain or network. Examples of organisations are Philips, Nedlloyd, and Frans Maas. Every organisation plays a certain role in a chain or network. This role relates an organisation to one or more processes in our model. Examples of roles are 'Philips as a production service provider', 'Nedlloyd as a logistic service provider', and 'Frans Maas as a transport service provider'.

Notice that organisations can play different roles in different chains and networks and that these roles can change in course of time. Therefore, these roles can differ in each instantiated model. For example, Philips can decide to distribute and transport some of its products itself. In other words, for these products Philips plays the role of production service provider, logistic service provider, and transport service provider at the same time.

The mapping of actors and processes has various reasons, such as economic, historical, or political reasons. These reasons form the basis of the interests of organisations, which largely explain their behaviour.

\subsection{Similar models}

Layered views of logistics are not new. The TRAIL research institute of the Delft University of Technology uses a similar four-layer reference model for describing the scope of their research program (Evers et al., 1994). Another model, consisting of three layers, is mentioned in an OECD report (OECD, 1992).

These models do not use the concepts of the ISO-OSI reference model. The model described by Linnartz (1991) does. His model consists of five layers: a social, interaction, transport, infrastructural and physical layer. In contrast with our model, which is based on a classification of primary processes, Linnartz structured his model using the classification of processes used in the ISO-OSI reference model. 


\section{THE TELEMATICS SUBMODEL}

Having described the logistic submodel, we will now focus on the description of the telematics submodel.

The ISO-OSI reference model, used for describing open distributed systems, consists of eight layers. To gain insight into existing and future telematics applications, it is not necessary to study all these layers in detail. Besides the interconnection aspects focussed upon by OSI, there is a growing need for interoperability. Therefore, ODP aspects must be taken into account as well (Schürmann, 1995).

We distinguish between three layers: a network layer, a generic application layer and a specific application layer for logistics. These layers and their relations are depicted in Figure 12. The network layer and the generic application layer emphasise interconnection aspects, while the interoperability aspects are more important in the specific logistic application layer. The network layer is described in Section 5.1, the generic application layer in Section 5.2, and the specific application layer for logistics in Section 5.3.

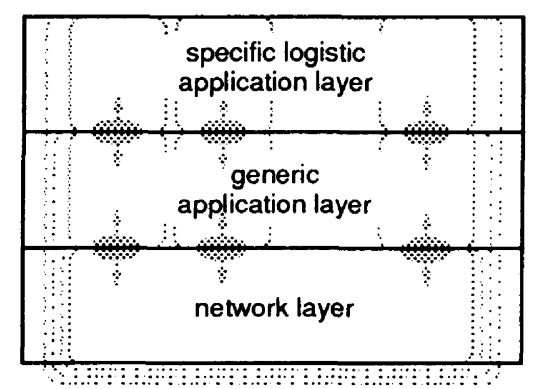

Figure 12 The telematics submodel.

\subsection{Network layer}

The network layer provides an end-to-end data transport service, using the physical telecommunication infrastructure. This layer corresponds to the layers $0, \ldots, 4$ of the ISO-OSI reference model. The network services can be distinguished using several dimensions, like the type of connection (fixed versus mobile), the type of communication (simplex versus duplex and multicast versus broadcast), and the geographical range.

These network dimensions determine the type of service provided by the network layer. Theoretically, this allows for many possible kinds of services. In practice however, not all possible combinations are provided. The network dimensions can be used to classify existing telecommunication services, like fixed or mobile telephone services, and satellite and beacon systems. It is also possible to identify new services for which no, or hardly any existing products or services are available. 


\subsection{Generic application layer}

The generic application layer takes care of the distributed storage and processing of and access to data, as well as the exchange of data. For bridging the physical distance, the described network services are used. Examples of generic application services are the following.

- Message handling services (E-mail) concern the transmission of short electronic messages. The sender is not bound to a specific message structure.

- EDI services provide a communication service for the exchange of structured data. The sender is committed to use the structure of the specific message. Structured messages can be read and implemented by automated systems of the receiver. Therefore, the messages can be processed without human interference.

- Isochronous/synchronous services offer a isochronous/synchronous data exchange for various types of data. An example of the use of such a service is videoconferencing, with which video, audio, and text are offered synchronously.

- Positioning services offer the possibility to determine the geographical location of an object. Both satellites and beacons can be used.

- Public page services provide the possibility to retrieve information from public pages.

\subsection{Specific logistic application layer}

For developing specific logistic telematics applications, it is necessary to describe the matching between the described submodels. In other words, it is necessary to determine in which way the exchange, storage, and processing of data in logistics can be supported by telematics applications. After analysing the information flows within and between logistic processes, the functional specifications for the supporting telematics applications can be defined. Using these specifications, applications can be implemented using existing or new components.

Within the logistic submodel, a structure of processes is described, in which complex interactions take place. These interactions encompass both the exchange of goods and the exchange of information. In order to determine the possibilities of the application of telematics, a thorough analysis of these interactions is necessary.

So far, this has not been included in our reference model. The services provided by the telematics applications, i.e. the exchange and processing of information, correspond to one or more interaction points within the logistic submodel. Both interaction points between, as well as within the logistic layers, are concerned. This is depicted in Figure 13.

Two examples of specific logistic applications are fleet management and navigation.

One of the important functions within fleet management is the communication between truck drivers and planners, for example using on-board terminals in trucks. This function of fleet management applications can be realised by using a message 
handling service and a mobile point-to-point data transmission service, like GSM or Inmarsat-C.

To find their way to loading and unloading addresses, truck drivers can use navigation equipment. These applications provide drivers with information on the cheapest or fastest way to a certain destination. In their simplest form, these applications consist of a database with route information, mostly stored on CD-ROMs, and a computer for retrieving, processing, and presenting route information to the driver. By using a positioning service, like GPS, and traffic information provided through RDS, a network service, these applications can also determine the location of the vehicle and can take into account incidents on the chosen route.

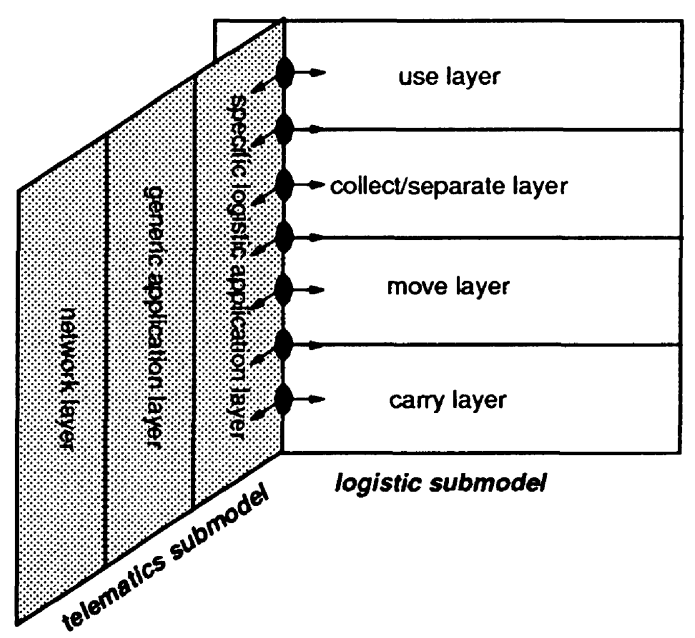

Figure 13 Reference model for logistics and telematics.

\section{OBJECTIVE OF AND MOTIVATION FOR A METHOD TO JUDGE FEASIBILITY}

The reference model can be used for describing and designing logistic networks. Another important use of the model is the determination or evaluation of the impact of telematics in a network. To do so, we need a method which enables us to analyse and compare specific situations represented by instances of the reference model. By taking two instances it is possible to compare the benefits of telematics in a new situation with its initial situation.

The method which we are developing, is aimed at enabling organisations to decide whether or not to change their processes by investing in telematics. Therefore, the method provides decision support. It must be able to compare instances of the reference model on both financial and non-financial consequences. In addition, the method takes both quantitative and qualitative factors into account.

In practice, organisations frequently have little notion of the impact of the use of a telematics application for their organisation and the entire logistic network. Often they also lack a quantitative basis to justify an investment in a telematics application (Dos 
Santos, 1991). Existing methods either focus on one aspect of the investment problem (mostly the financial or technical aspect) or on a part of the logistic network.

Cost-benefit analyses are difficult to perform and take only financial aspects of the application into account. Initial investment in the application can mostly be quantified, but an assessment of the expected benefits and the development of the costs in the following stages of telematics-use is difficult (Oirsouw et al., 1993). Besides, most cost-benefit analysis methods neglect many other (qualitative) factors, which influence the success of a telematics application. This leads to decisions for telematics applications on the basis of expected, but highly uncertain benefits (Mahmood and Mann, 1993).

Such decision behaviour is imaginable, given the complexity of the problem. Although their applicability is limited, existing methods are quite useful and work well. Yet, decisions taken on the basis of these methods may lead to unexpected results and sub-optimisation (Reekers and Smithson, 1994). Our method is based on a broader foundation and comprises eventually (parts) of other analysis methods.

\section{A METHOD FOR THE A PRIORI ASSESSMENT OF FEASIBILITY ASPECTS}

For the development of the method we use a stepwise approach. This approach is represented in Figure 14.

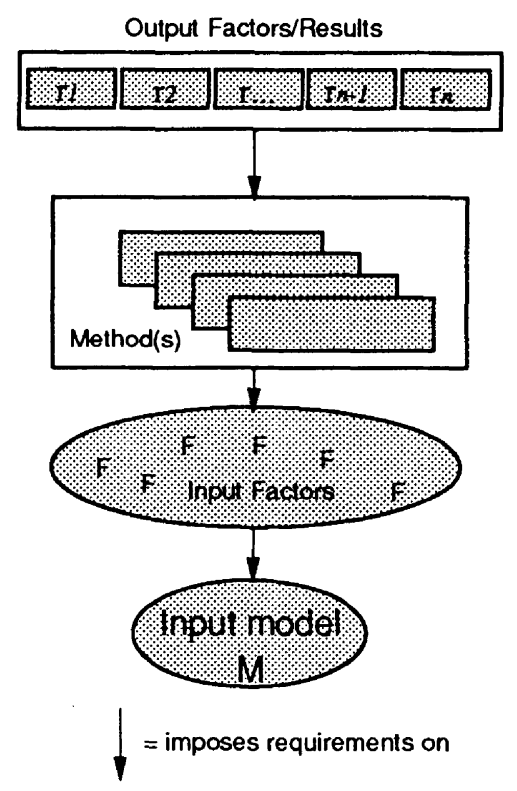

Figure 14 Approach for the design of the method.

We started with determining what kind of outcome is desirable and what form it should take. The result of the method is a set of output factors representing properties of the situation expressed by an instance of the described model. At this moment, we distinguish the following classes of output factors: financial, commercial, technical, operational, organisational, socio-economical, and environmental classes (partly based on Verweij et al., 1994). 
Eventually, the user of the method should judge the situation represented by the instance, considering the results of the method and his or her own interest (a shipper's evaluation of the results may differ from that of a policy maker or a carrier). For example, the use of tracking and tracing services may lead to a positive effect on the financial and technical classes for a cluster of functions within the network. The organisation which executes this cluster (a carrier) will judge positively on the telematics use, whereas the other organisations in the network do not directly benefit and hence may give a negative judgement.

The output factors determine the input factors as well as their relation with the input factors. This dependence is expressed in various analysis methods. Because of the diversity of the classes of output factors (the financial class is quite different from the environmental class), we cannot make use of a single analysis method. The diversity makes it necessary to develop a combination of existing analysis methods and newly developed methods. There must be a balance between economic, social, and technical methods and between methods which can analyse quantitative and qualitative factors.

Besides the methods combining quantitative and qualitative analysis for investment decisions in CIM and Flexible Manufacturing Systems, we might use analysis methods like Activity-Based Costing, Multi-Criteria Analysis and Function-Point Analysis. We have started with the study of Activity-Based Costing (ABC) (Cooper, 1988). Parts of this product costing technique are useful, because $\mathrm{ABC}$ traces costs to products according to the activities performed on them. The use of activities in ABC can be mapped to the reference model because the reference model constructs logistic networks on the basis of processes (activities is synonymous to processes). Moreover, the functions which $\mathrm{ABC}$ can perform, i.e. cost management, process control, and responsibility reporting, are separated from each other, as opposed to traditional cost accounting systems. This makes it easier to use the parts of ABC we need.

The next step is to search for other analysis methods which can be combined within the overall method. These determine in what form the instances need to be extracted from the reference model.

Parallel to the study of analysis methods, we have already started with a search for input factors. The current set of input factors is composed via literature search, interviews with experts and based on case material (Verweij et al, 1994; Magal et al., 1988; Oirsouw et al., 1993; Schuurman, 1994; Teeuw et al., 1994). This set of factors is broader than the sets found in literature and comprises all kinds of factors, varying from hardware costs to the complexity of the environment. However, the set is not complete and must be structured (for instance to minimise mutual dependencies between input factors). It is possible that the output factors in the different classes depend on the same input factors. Such dependencies are determined by the method used in each case. The method is not the same for every class. For example, the input factor 'total amount of travelled miles' will be reflected in the financial class of output factors and in the environmental class of output factors.

The input factors form the linking pin between the reference model and the method. The reference model must enable the extraction of the input factors from its instances. 
The method has the following advantages.

- It is integrated with the reference model, which provides a fundamental and structured manner to analyse and improve logistic networks.

- It integrates both quantitative and qualitative factors.

- It supports its users to analyse a new situation in advance as well as to evaluate the situation afterwards.

\section{STATE OF THE RESEARCH AND FURTHER WORK}

In the previous sections, we have given an overview of the research performed at TRC considering the analysis and (re)design of logistic networks. We introduced a reference model by which we can describe an entire logistic network in a systematic manner. This first step of our modelling activities resulted in a classification of logistic and telematics services. This classification provides a structured view on logistics, which turned out to be very useful to describe logistic activities in several projects.

However, to be able to describe logistic networks in more detail, we need to decompose these layers into different generic process descriptions, i.e. building blocks, which can be used to construct specific chain or network situations. These generic building blocks can then be used to describe almost any logistic situation based on which a thorough analysis of the application of telematics can be obtained.

Future work related to the model, therefore concerns the following.

- A further decomposition of secondary processes into control and information processes, including descriptions of their interactions and behaviour, is necessary.

- The classification of processes must be further decomposed into process descriptions which can be used as generic building blocks for constructing instantiated models.

- The model needs to be validated using case-material.

Future work for the method comprises the following steps.

- The classes with output factors must be fine-tuned and defined more clearly.

- The set of input factors must be completed and structured, dependent on the output factors and the analysis methods.

- The analysis method needs to be completed and validated with case material.

The surplus value of the research lies in the combined use of the reference model and the method. Although the described model and method are only a first step to a systematic approach to the analysis and (re)design of logistic networks, the results are encouraging. 


\section{REFERENCES}

Aalst, W.M.P. van der (1992) Timed Coloured Petri Nets and their Application to Logistics. Dissertation, Eindhoven University of Technology, Eindhoven, The Netherlands.

Biemans, F.P.M. (1989) A Reference Model for Manufacturing Planning and Control. Dissertation, University of Twente, Enschede, The Netherlands.

Bowersox, D.J., D.J. Closs and O.K. Helferich (1986) Logistical Management - A Systems Integration of Physical Distribution, Manufacturing Support and Materials Procurement. Third edition. Macmillan Publishing Company, New York.

Cooper, R. (1988-1989) The Rise of Activity-Based Costing - Part One: What is an Activity-Based Cost System. Journal of Cost Management, Summer 1988: 45-54.

Dos Santos, B.L. (1991) Justifying Investments in New Information Technologies. Journal of Management Information Systems, 7(4): 71-90.

Evers, J.J.M., P.H.L. Bovy, J.L. de Kroes, et al. (1994) Transport, infrastructuur en logistiek: een proeve van een integrerend onderzoeksprogramma. TRAIL studies No. 94-1. TRAIL Onderzoekschool, Delft, The Netherlands. (In Dutch)

Goor, A.R. van, A.H.L.M. Kruijtzer and G.W. Esmeijer (1993) Goederenstroombesturing, voorraadbeheer en materials handling. Second edition. Stenfert Kroese, Leiden, The Netherlands. (In Dutch)

Hofman, W.J. (1994) A Conceptual Model of a Business Transaction Management System. Dissertation, Eindhoven University of Technology. Tutein Nolthenius/Bakkenist, Spits en Co, 's-Hertogenbosch, The Netherlands.

ISO (1984) Information Processing Systems - Open Systems Interconnection Basic Reference Model. International Standard ISO/DIS 7498. Geneva, Switzerland.

Lambert, D.M. and J.R. Stock (1993) Strategic Logistics Management. Third edition. Irwin, Homewood, USA.

Lewis, L. (ed.) (1986) Information Technology in Physical Distribution. Technical Press, Aldershot, UK.

Liefting, J.R., P.W. van der Veer, P.H.W.M. Oude Luttighuis, et al. (1994) Basismodel TIVV - Subgroep Generieke Basisfuncties, Rapportage fase 2. Raamwerkstudie Telematica-Infrastructuur Verkeer \& Vervoer, Subgroep Generieke Basisfuncties, Den Haag, The Netherlands. (In Dutch)

Linnartz, J.P.M.G. (1991) Verkeer met snelheidsbegrenzers of met lichtsnelheid? Informatie en Informatiebeleid. 9(3): 25-35. (In Dutch)

Magal, S.R., H.H. Carr and H.J. Watson (1988) Critical Success Factors for Information Center Managers. MIS Quarterly, September 1988: 413-424.

Mahmood, M.A. and G.J. Mann (1993) Measuring the Organizational Impact of Information Technology Investment - An Exploratory Study. Journal of Management Information Systems, 10(1): 97-122.

OECD (1992) Road Transport Research - Advanced Logistics and Road Freight Transport. Organisation for Economic Co-operation and Development, Paris, France.

Oirsouw, R. van, J. Spaanderman and H. de Vries (1993) Informatie Economie Investeringsstrategie voor de informatievoorziening. Academic Service, Schoonhoven, The Netherlands. (In Dutch) 
Pfohl, H.-Ch. (1990) Logistik-systeme - Betriebwirtschafliche Grundlagen. Fourth edition. Springer-Verlag, Berlin, Germany. (In German)

Reekers, N. and S. Smithson (1994) The distribution of the benefits and drawbacks of EDI use in the European automotive industry, in: Proceedings of the Fifth World Congress of EDI users (ed. R. Till), Brighton, UK.

Schrijver, P.R. (1993) Supporting Fleet Management by Mobile Communications. Dissertation, Delft University of Technology, Delft, The Netherlands.

Schürmann, G. (1995) The evolution from open systems interconnection (OSI) to open distributed processing (ODP). Computer Standards \& Interfaces, 17(1):107-113.

Schuurman, W.P.J.A.M. (1994) Management of Distribution Logistics. Report No. TRC-RS/94012, Telematics Research Centre, Enschede, The Netherlands.

Sinderen, M. van, L. Ferreira Pires, C.A. Vissers, et al. (1995), A design model for open distributed processing systems. Computer Networks and ISDN Systems, 27(8): 1263-1285.

Tanenbaum, A.S. (1981) Computer Networks. Prentice/Hall, Englewood Cliffs, USA.

Taylor, K. (1991) Computer Systems in Logistics and Distribution. Kogan Page, London, UK.

Teeuw, W.B., J.R. Liefting and R.H.J. Demkes (1994) Product Data Interchange Towards successful introduction of PDI in practice. Report No. IRS/94015, Telematics Research Centre, Enschede, The Netherlands.

Verweij, K., R. ter Brugge, and F. Ballhaus (1994) General evaluation framework to assess the impacts of ATT-applications in freight transport, in: Towards an Intelligent Transport System - Proceedings of the first world congress on applications of transport telematics and intelligent vehicle-highway systems, 3: 1452-1459, ERTICO, Paris, France.

Williams, T.J., P. Bernus, J. Brosvic, et al. (1994) Architectures for integrating manufacturing activities and enterprises. Computers in Industry, 24(2-3): 111-139. 